NASA/TM-2018-219765

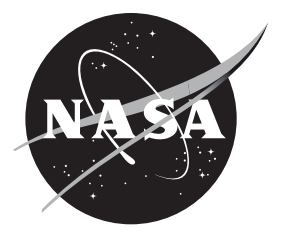

\title{
An Intelligent Propulsion Control Architecture to Enable More Autonomous Vehicle Operation
}

Jonathan S. Litt

Glenn Research Center, Cleveland, Ohio

T. Shane Sowers

Vantage Partners, LLC, Brook Park, Ohio

Donald L. Simon and A. Karl Owen

Glenn Research Center, Cleveland, Ohio

Aidan W. Rinehart and Amy K. Chicatelli

Vantage Partners, LLC, Brook Park, Ohio

Michael J. Acheson and Richard M. Hueschen

Langley Research Center, Hampton, Virginia

Christopher W. Spiers

Glenn Research Center, Cleveland, Ohio 


\section{NASA STI Program . . . in Profile}

Since its founding, NASA has been dedicated to the advancement of aeronautics and space science. The NASA Scientific and Technical Information (STI) Program plays a key part in helping NASA maintain this important role.

The NASA STI Program operates under the auspices of the Agency Chief Information Officer. It collects, organizes, provides for archiving, and disseminates NASA's STI. The NASA STI Program provides access to the NASA Technical Report Server-Registered (NTRS Reg) and NASA Technical Report ServerPublic (NTRS) thus providing one of the largest collections of aeronautical and space science STI in the world. Results are published in both non-NASA channels and by NASA in the NASA STI Report Series, which includes the following report types:

- TECHNICAL PUBLICATION. Reports of completed research or a major significant phase of research that present the results of NASA programs and include extensive data or theoretical analysis. Includes compilations of significant scientific and technical data and information deemed to be of continuing reference value. NASA counter-part of peer-reviewed formal professional papers, but has less stringent limitations on manuscript length and extent of graphic presentations.

- TECHNICAL MEMORANDUM. Scientific and technical findings that are preliminary or of specialized interest, e.g., "quick-release" reports, working papers, and bibliographies that contain minimal annotation. Does not contain extensive analysis.
- CONTRACTOR REPORT. Scientific and technical findings by NASA-sponsored contractors and grantees.

- CONFERENCE PUBLICATION. Collected papers from scientific and technical conferences, symposia, seminars, or other meetings sponsored or co-sponsored by NASA.

- SPECIAL PUBLICATION. Scientific, technical, or historical information from NASA programs, projects, and missions, often concerned with subjects having substantial public interest.

- TECHNICAL TRANSLATION. Englishlanguage translations of foreign scientific and technical material pertinent to NASA's mission.

For more information about the NASA STI program, see the following:

- Access the NASA STI program home page at http://www.sti.nasa.gov

- E-mail your question to help@sti.nasa.gov

- $\quad$ Fax your question to the NASA STI Information Desk at 757-864-6500

- Telephone the NASA STI Information Desk at 757-864-9658

- Write to:

NASA STI Program

Mail Stop 148

NASA Langley Research Center Hampton, VA 23681-2199 
NASA/TM-2018-219765

AIAA-2018-1837

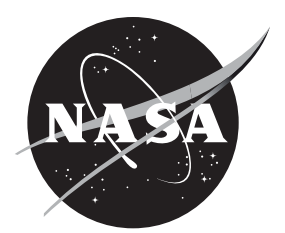

\section{An Intelligent Propulsion Control Architecture to Enable More Autonomous Vehicle Operation}

Jonathan S. Litt

Glenn Research Center, Cleveland, Ohio

T. Shane Sowers

Vantage Partners, LLC, Brook Park, Ohio

Donald L. Simon and A. Karl Owen

Glenn Research Center, Cleveland, Ohio

Aidan W. Rinehart and Amy K. Chicatelli

Vantage Partners, LLC, Brook Park, Ohio

Michael J. Acheson and Richard M. Hueschen

Langley Research Center, Hampton, Virginia

Christopher W. Spiers

Glenn Research Center, Cleveland, Ohio

Prepared for the

SciTech Forum 2018

sponsored by the American Institute of Aeronautics and Astronautics

Kissimmee, Florida, January 8-12, 2018

National Aeronautics and

Space Administration

Glenn Research Center

Cleveland, Ohio 44135 


\section{Acknowledgments}

The authors gratefully acknowledge the Program Directors of the NASA Advanced Air Vehicles Program (AAVP) and the Transformative Aeronautics Concepts Program (TACP), who jointly sponsored this research.

Trade names and trademarks are used in this report for identification only. Their usage does not constitute an official endorsement, either expressed or implied, by the National Aeronautics and Space Administration.

This work was sponsored by the Advanced Air Vehicle Program at the NASA Glenn Research Center

Level of Review: This material has been technically reviewed by technical management.

Available from

NASA STI Program

Mail Stop 148

NASA Langley Research Center

Hampton, VA 23681-2199
National Technical Information Service 5285 Port Royal Road Springfield, VA 22161 703-605-6000

This report is available in electronic form at http://www.sti.nasa.gov/ and http://ntrs.nasa.gov/ 


\title{
An Intelligent Propulsion Control Architecture to Enable More Autonomous Vehicle Operation
}

\author{
Jonathan S. Litt \\ National Aeronautics and Space Administration \\ Glenn Research Center \\ Cleveland, Ohio 44135 \\ T. Shane Sowers \\ Vantage Partners, LLC \\ Brook Park, Ohio 44142 \\ Donald L. Simon and A. Karl Owen \\ National Aeronautics and Space Administration \\ Glenn Research Center \\ Cleveland, Ohio 44135 \\ Aidan W. Rinehart and Amy K. Chicatelli \\ Vantage Partners, LLC \\ Brook Park, Ohio 44142 \\ Michael J. Acheson and Richard M. Hueschen \\ National Aeronautics and Space Administration \\ Langley Research Center \\ Hampton, Virginia 23666 \\ Christopher W. Spiers \\ National Aeronautics and Space Administration \\ Glenn Research Center \\ Cleveland, Ohio 44135
}

\begin{abstract}
This paper describes an intelligent propulsion control architecture that coordinates with the flight control to reduce the amount of pilot intervention required to operate the vehicle. Objectives of the architecture include the ability to: automatically recognize the aircraft operating state and flight phase; configure engine control to optimize performance with knowledge of engine condition and capability; enhance aircraft performance by coordinating propulsion control with flight control; and recognize off-nominal propulsion situations and to respond to them autonomously. The hierarchical intelligent propulsion system control can be decomposed into a propulsion system level and an individual engine level. The architecture is designed to be flexible to accommodate evolving requirements, adapt to technology improvements, and maintain safety.
\end{abstract}

\section{Nomenclature}

$\begin{array}{ll}\text { IA } & \text { Increasing Autonomy } \\ \text { IFC } & \text { Intelligent Flight Control } \\ \text { IPC } & \text { Intelligent Propulsion Control } \\ \text { IMM } & \text { Intelligent Mission Management } \\ \text { OEI } & \text { One Engine Inoperative }\end{array}$




\section{Introduction}

Economic pressure on airlines and a pilot shortage (Ref. 1) are providing the impetus to reduce the size of the cockpit crew, and eventually remove the pilot altogether, once the idea gains acceptance with the flying public (Ref. 2). With the current high level of automation, it might seem like a short leap to a single pilot in the cockpit, to a fully unpiloted vehicle, or to a single pilot on the ground monitoring multiple vehicles at once. Currently, in highly automated modern commercial aircraft, pilots spend an average of under 7 min per flight actually flying the aircraft (Ref. 3). This hand flying occurs almost exclusively during takeoff and landing (Ref. 4), which is also when most accidents and incidents take place (Ref. 5). It should not be surprising that lack of participation in the flying process can lead to boredom, which can lead to a decrease in performance (Ref. 6). High profile accidents (Refs. 7 and 8) point out not only the loss of piloting skills, but also confusion about the automation itself (Ref. 9). However, pilots can also identify extremely unusual emergency situations and demonstrate tremendous skill in reacting to them (Refs. 10 to 12). This reveals a paradox: while most commercial aviation accidents are attributed to human error (Ref. 13), humans can also prevent accidents through heroic action that cannot be anticipated or learned through training. Therefore, any system that replaces the pilot flying must not only perform as well as or better than the human on mundane tasks, it must exceed the human in extraordinary situations, or risk that the promise of autonomous aircraft will not be fulfilled.

Approaches to the design of such a system can be through either comprehensive automation, or automation that has the ability to reason about situations it was not explicitly designed to address. The latter approach would involve the development of sufficient vehicle self-awareness to at least replace the pilot's senses when it comes to diagnosing problems.

Autonomous operation of civil aircraft will require the propulsion control to be highly integrated with the flight control to remove the need for the pilot to serve as the integrator. This integration can also provide an added benefit of overall system optimization. Although recognition of off-nominal situations in the propulsion system is one of the capabilities at which pilots excel, pilot error is still cited as the cause of most accidents. Therefore, on-board autonomy algorithms will need to be able to recognize and respond to off-nominal propulsion situations even better than pilots do today. There are numerous examples of propulsion system malfunction plus inappropriate crew response (Ref. 14) leading to accidents. Addressing these situations through greater engine state awareness and better communication to the pilot is the initial step, with the autonomy taking on more responsibility over time.

The specific goal here is to develop an intelligent engine control architecture that enables the propulsion system to work harmoniously with the flight control, with reduced pilot intervention required as the architectural framework is populated. It will automatically recognize the vehicle operating mode and configure the engine control scheme to provide optimal performance for that mode based on knowledge of engine condition and capability. The propulsion control will take cues from the flight control to operate autonomously. It enables "personalized" control of an engine, which will facilitate the ability to assess the current engine condition and its performance. The architecture provides an interface with the flight control to communicate engine capability, receive engine thrust commands, and set the engine into the appropriate control mode; it also enables safe accommodation of "off-nominal" conditions by intelligent decision making to replace decisions currently made by the pilot - such as whether to shut down an engine, continue operating at reduced performance, etc. Increased system integration will result in enhanced information that will ultimately improve safe decision making. There will be a natural progression from the current situation where the pilot monitors and controls the engine to a fully autonomous propulsion system. This approach will maintain safety and still be compatible with an increasingly autonomous flight control.

The remainder of this paper consists of a description of the architecture, followed by several examples of the partially populated architecture implemented and operating in a simulation testbed to identify and mitigate safety concerns. A discussion of the examples and a lessons learned section come next, followed by conclusions. 


\section{Intelligent Propulsion System Control Architecture}

With advancements in computing and information systems technology, it is reasonable to assume that there will be a natural progression from the current cockpit procedures to fully autonomous aircraft operation. The intelligent propulsion system control architecture must be flexible enough to accommodate evolving requirements while maintaining safety (note that some recent accidents have been attributed to loss of piloting skills due to over-reliance on automation (Ref. 15)). Therefore, the types of functions currently performed by pilots, as well as those that would need to be performed with no pilot present, must be addressed. These types of functions include detecting, diagnosing (Ref. 16), and accommodating faults (Figure 1), and reducing pilot workload in high stress situations. They can extend to optimizing aircraft performance by coordinating the flight and propulsion control under certain situations, without an explicitly integrated flight and propulsion control design approach. An intelligent propulsion control architecture has been developed, as shown in Figure 2. The intelligent propulsion control comprises the engine systems with their individual controls at the lowest level, along with the propulsion system level above them. In parallel is a presumably similar, although undefined, flight control structure (this flight control structure should support such functionality as reconfiguration in response to a stuck actuator or damaged flight control surface (Ref. 17), for example). Above these two structures is an Intelligent Mission Management (IMM) level, which coordinates the flight and propulsion control as necessary. This architecture maintains the traditional roles of distinct flight and propulsion control systems as is standard practice today, but supports integrated flight and propulsion control as necessary to accommodate faults or optimize performance. Thus, the architecture is suitable for a progression from current practice to a more fully integrated design, as might be expected in the future. To enable this progression, more and more of the intelligent decision-making pilot function can be done autonomously, similar to how automation has assumed much of the role of flying today.

\begin{tabular}{|c|c|c|c|c|c|c|c|c|c|c|c|c|c|}
\hline & 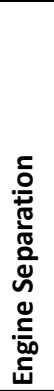 & 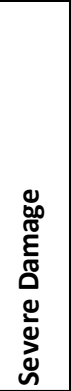 & 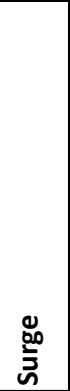 & 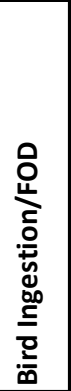 & 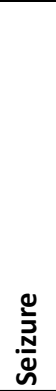 & 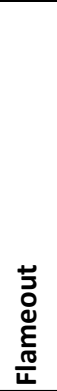 & $\begin{array}{l}\frac{\tilde{E}}{0} \\
\frac{0}{0} \\
\frac{0}{0} \\
\frac{0}{0} \\
0 \\
\frac{0}{0} \\
\frac{0}{0} \\
\frac{0}{4}\end{array}$ & $\stackrel{\varrho}{\stackrel{\Xi}{*}}$ & 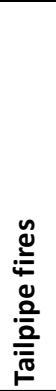 & 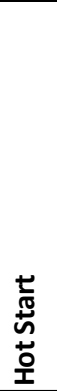 &.$\stackrel{\infty}{\underline{E}}$ & 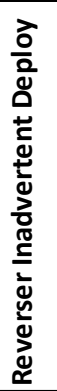 & 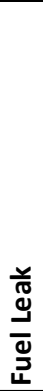 \\
\hline Bang & 0 & $x$ & $x$ & 0 & 0 & & & & & & 0 & & \\
\hline Fire warning & 0 & 0 & & 0 & & & & $\mathrm{x}$ & & & & & \\
\hline Visible flame & 0 & 0 & 0 & 0 & & & & 0 & $\mathrm{x}$ & 0 & & & \\
\hline Vibration & & $\mathrm{x}$ & 0 & $\mathrm{x}$ & 0 & & & & & & $\mathrm{x}$ & $\mathrm{x}$ & \\
\hline Yaw & 0 & 0 & 0 & 0 & 0 & 0 & 0 & & & & & $\mathrm{x}$ & \\
\hline High EGT & & $x$ & $\mathrm{x}$ & 0 & 0 & & $\mathrm{x}$ & & 0 & $\mathrm{x}$ & 0 & & \\
\hline N1 change & $\mathrm{x}$ & $\mathrm{x}$ & 0 & 0 & $\mathrm{x}$ & $\mathrm{x}$ & $\mathrm{x}$ & & & & & & $\mathrm{x}$ \\
\hline N2 change & $\mathrm{x}$ & $\mathrm{x}$ & 0 & 0 & $\mathrm{x}$ & $\mathrm{x}$ & $\mathrm{x}$ & & & & & & $\mathrm{x}$ \\
\hline Fuel flow change & $\mathrm{x}$ & 0 & 0 & & 0 & $\mathrm{x}$ & 0 & 0 & & & & & $\mathrm{x}$ \\
\hline Oil indication change & $\mathrm{x}$ & 0 & 0 & & 0 & $\mathrm{x}$ & & 0 & & & & & \\
\hline Visible cowl damage & $\mathrm{x}$ & $\mathrm{x}$ & & & & & & 0 & & & & $\mathrm{x}$ & \\
\hline Smoke/odor in cabin bleed air & & 0 & & 0 & 0 & & & & & & & & \\
\hline EPR change & $\mathrm{x}$ & $\mathrm{x}$ & $\mathrm{x}$ & 0 & $\mathrm{x}$ & $\mathrm{x}$ & $\mathrm{x}$ & & & & & & $\mathrm{x}$ \\
\hline
\end{tabular}

Figure 1.-Propulsion system malfunctions and observed symptoms (from Ref. 16). 


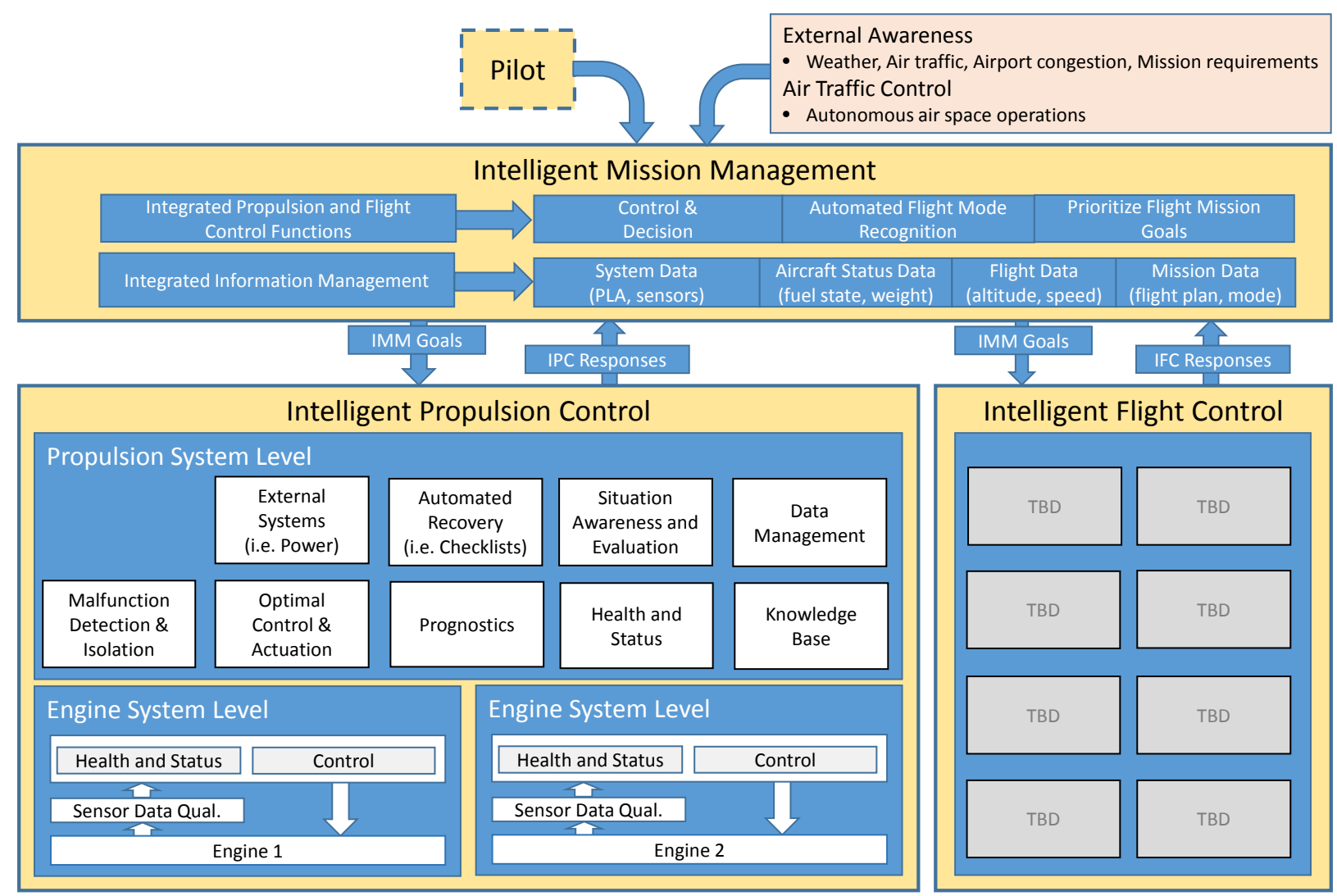

Figure 2.-Intelligent propulsion control architecture.

The hierarchical nature of this architecture is advantageous, since it can be populated from the bottom up, meaning that existing subsystem and engine level diagnostic algorithms can be implemented initially, while higher level functions that depend on them to enable autonomous operation can be added later. This strategy builds on years of development of algorithms for engine health management, diagnostics, prognostics, estimation, and control (Ref. 18), and directly supports the concept of increasing autonomy (IA) (Ref. 19). Increasingly autonomous systems are defined as lying along the spectrum of system capabilities that begin with the abilities of current automatic systems, such as autopiloted and remotely piloted (nonautonomous) unmanned aircraft, and progress toward highly sophisticated systems. For the purposes of this work, autonomy is defined as a process that occurs without human intervention, and increasing autonomy means that the complexity or abstraction of the procedure increases. For instance, the appropriate pilot responses to a variety of engine malfunctions are defined in the aircraft flight manual. These checklist procedures define the sequence of steps that pilots are to follow in the event of a given malfunction. With IA, the engine level algorithms might help diagnose a problem, which could lead to execution of the appropriate checklist. Eventually, as the higher levels of the architecture are populated with algorithms, evaluation of the situation and reasoning about any actions that are currently up to the pilot's discretion could be achieved. The distinction between intelligence and autonomy is somewhat blurred, but here it means that the diagnostic, prognostic, and - to an extent-accommodation algorithms build on and support each other to produce actionable knowledge about the engine and its operational capabilities (intelligence), which can be used to re-plan the mission or perform other higher level functions (autonomy). 
Basic definitions of the functional blocks comprising the architecture in Figure 2 are described next.

\section{Intelligent Mission Management (IMM) \\ Integrated Propulsion and Flight Control Functions}

- Control and Decision-Issues command goals to the intelligent control elements and monitors progress.

- Automated Flight Mode Recognition-Determines the phase of flight.

- Prioritize Flight Mission Goals—Specifies the overall flight mission objectives.

Integrated Information Management

- System Data-Sensor data and cockpit control setting information.

- Aircraft Status Data-Information on the aircraft status (e.g., weight, fuel quantity).

- Flight Data-Information on the status of the flight (e.g., vertical speed, airspeed, altitude, bank angle).

- Mission Data-Information of the overall flight (e.g., planned cruising altitude, current flight segment, planned airspeed).

Goals and Responses

- IMM Goals_- “Goals” sent from the Intelligent Mission Management level to the lower level control elements. These are considered goals rather than commands so that each individual intelligent control element can determine its own optimal approach to satisfy the IMM objective.

- IPC/IFC Responses - Status of the goal response sent back to IMM. Provides information on whether the goal is achievable and its status, allowing the IMM to determine if the command goals should be modified to something more achievable.

Intelligent Propulsion Control (IPC)

- Propulsion System Level-Intelligent control level that oversees the entire propulsion system. Most of the propulsion intelligence resides at this level. A process continuously performs the Observe, Orient, Decide and Act (OODA) decision loop on the command goals for the propulsion system.

o External System - Controls engine auxiliary output, which includes electric power generation and cabin bleed air.

o Automated Recovery-Performs automated pilot check list actions for events to reduce pilot workload.

o Situation Awareness and Evaluation-Determines situation and decides if current trends are desirable or if further action is necessary.

o Data Management-Manages the data flow throughout the IPC.

o Malfunction Detection and Isolation-Actively senses and implements mitigating actions (i.e., executes the appropriate checklists) for propulsion system faults.

o Optimal Control and Actuation-Determines how the engines can be operated to achieve a desired goal such as increased efficiency or performance considering condition of the engines, current flight environmental conditions and the given flight plan.

o Prognostics-Forecasts future propulsion system health status (i.e., life available). May estimate time to failure during an engine fault (e.g., time to engine seizure resulting from an oil leak).

o Health and Status-Determines and monitors overall propulsion system health status.

o Knowledge Base-A repository of information used by the IPC to make decisions. It can be updated with information that has been "learned."

- Engine System Level-The level is mostly an interface to the engine controller with some logic to enhance functionality.

o Health and Status_-Determines engine health status.

o Control-An interface to the engine controller (Full Authority Digital Engine Control, or FADEC).

o Sensor Data Qualification -Evaluates engine sensor data to validate that the data are correct.

Intelligent Flight Control (IFC)

- Function elements are TBD.

There are multiple advantages of this architecture: pilot workload can be reduced; flight safety can be improved; aircraft performance can be enhanced; flight operations can be accomplished in a more efficient and cost effective manner; and actionable knowledge can be produced and exploited. 


\section{Demonstration}

Intelligent propulsion control provides oversight, diagnostics, advice, and automated responses, so it can work with the pilot or on its own to improve safety and performance. Knowledge of the engine state can be critical in emergencies because it can provide guidance for an appropriate response. In the Kegworth air disaster of 1989 (Ref. 20), a fan blade on a British Midland-operated Boeing 737-4Y0 detached, resulting in heavy vibration and smoke in the cabin. The pilot misdiagnosed the problem engine based on an incorrect understanding of the ventilation system, and shut down the wrong engine, unknowingly continuing to fly on the bad one. Eventually, the damaged engine ceased operating and burst into flames, resulting in a deadly crash. In another example, TransAsia Airways Flight 235, a twin-engine turboprop, experienced an engine flameout on takeoff. The flight crew did not perform the appropriate failure identification procedure, resulting in confusion regarding the identification and nature of the actual propulsion system malfunction. The pilot reduced power on the working engine and then shut it down (Ref. 21). The aircraft climbed, and before the engines could be restarted, it stalled. The altitude was insufficient for recovery, and the plane crashed.

With knowledge of the engine state, the preliminary implementation of the intelligent propulsion control architecture is able to flag engines as good/working or bad/nonworking/failed, so that a pilotinitiated in-flight shutdown of a good engine is inhibited or at least the pilot is alerted. The following examples focus on situations that are easy to visualize; the underlying algorithms and their resulting diagnoses and actions represent only a small subset of the potential features of the fully populated architecture.

\section{Testbed}

The testbed used for evaluation was the Transport Class Model (TCM) (Ref. 22) airframe simulation integrated with two copies of the Commercial Modular Aero-Propulsion System Simulation 40k (C-MAPSS40k) (Refs. 23 and 24) engine model in the NASA Glenn flight simulator (Ref. 25). The TCM represents a generic, mid-sized, single-aisle transport aircraft with two wing-mounted engines.

C-MAPSS40k models a 40,000-lbf thrust class, high-bypass ratio turbofan engine with a representative commercial-type controller. There have been multiple control and diagnostic algorithms demonstrated using the combined simulation (Refs. 26 to 28), or C-MAPSS40k (Refs. 29 to 31) by itself, so the initial implementation of the architecture framework was in place.

\section{Examples}

The examples presented below involve engine malfunctions and shutdowns, and their impact on the vehicle. Commercial aircraft are designed to fly safely with an engine out. Normally with both engines functioning, the throttles are moved together to produce symmetric thrust. When there is one engine inoperative (OEI), the pilot is presented with flying challenges due to the off-centerline thrust from the remaining engine, which affects control of the aircraft in yaw, pitch and roll. Flight control surfaces are designed to be large enough to counteract this imbalance, but will incur an associated performance penalty. Because flight control effectiveness is related to airspeed, thrust imbalance is more difficult to counteract when the aircraft flies slowly. At faster airspeeds, flight control authority is improved and the aircraft is much easier to manage.

When there is an OEI with a twin engine aircraft, there is the expected loss of 50 percent of the available thrust, but there is a more significant loss of performance from the aircraft flying in an uncoordinated fashion. There is added drag resulting from the flight control inputs needed to offset the thrust imbalance, and from the drag penalty originating from the inoperative engine. These performance impairments must be managed as much as possible by the pilot to reduce their impact. 
When an engine fails, it may be difficult to determine which one it is initially. Because of windmilling of the inoperative engine, both engines may appear to be functioning, since the instruments of the failed engine have readings that may make it seem as though it is still functioning.

The above background provides some context for the following three examples.

\section{Propulsion System Malfunction Detection and Identification}

The first case demonstrates propulsion system diagnostics. Here, the right engine is severely deteriorated and cannot produce as much thrust as the left engine. This is clear from the top two plots in Figure 3. While the throttles are moved together to the same power settings, the estimated thrust (Ref. 32) of the two engines is very different, especially at high power. The third plot shows that this leads to a temporary declaration of asymmetric thrust, which is subsequently unflagged as power is reduced and the thrust mismatch decreases at about $46 \mathrm{~s}$. However, a power demand increase at about $85 \mathrm{~s}$ again results in an asymmetric thrust declaration. The right engine begins to shut down at about $92 \mathrm{~s}$, and the output of the shutdown detection logic that flags it is shown in the fourth plot.
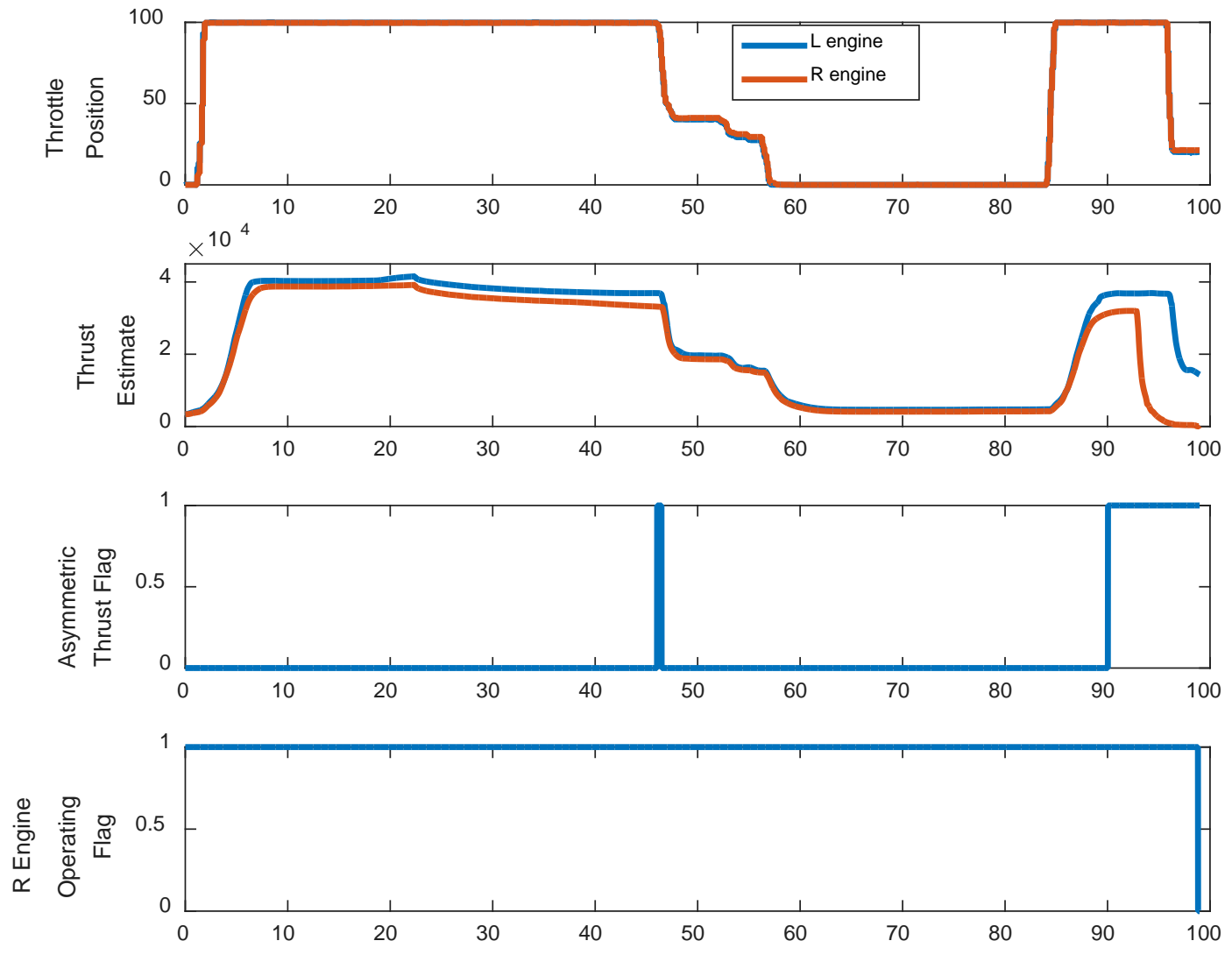

Figure 3.-Engine diagnostics demonstration. 


\section{Engine Shutdown Inhibition}

This second example exercises different aspects of the architecture, using the same set of simulated flight data as the first example, to demonstrate how a commanded engine shutdown can be inhibited under unsafe conditions. The logic bases safety for such an action on a minimum airspeed or height above ground (AGL), either 135 knots or $1000 \mathrm{ft}$ AGL in this case. Here the pilot attempts to shut down the engine after observing the abnormal behavior in the previous example. As shown in Figure 4, the command is given at about $83 \mathrm{~s}$, but because the aircraft is too low and too slow according to the oversight logic, the shutdown is inhibited until about $93 \mathrm{~s}$, when the system deems that the flight conditions are safe. This adds a layer of protection, but can be overridden by the pilot, if necessary.

\section{One Engine Inoperative Vehicle Upset Recovery}

The final example demonstrates minimum control airspeed protection against loss of control for an engine out situation (Figure 5). In this example, the right engine goes out (at about $10 \mathrm{~s}$ ) and the airspeed begins to reduce. As the speed drops below the minimum control airspeed, the rudder loses effectiveness, making it unable to counteract the thrust asymmetry, and the plane begins to roll into an upset condition. However, in this case, the good engine's thrust is cut back temporarily to remove the asymmetry and arrest the roll departure. This happens a couple of times (at about 20 and $30 \mathrm{~s}$ ), at which point the airspeed has increased enough due to a reduction in pitch to return rudder effectiveness allowing the aircraft to recover.
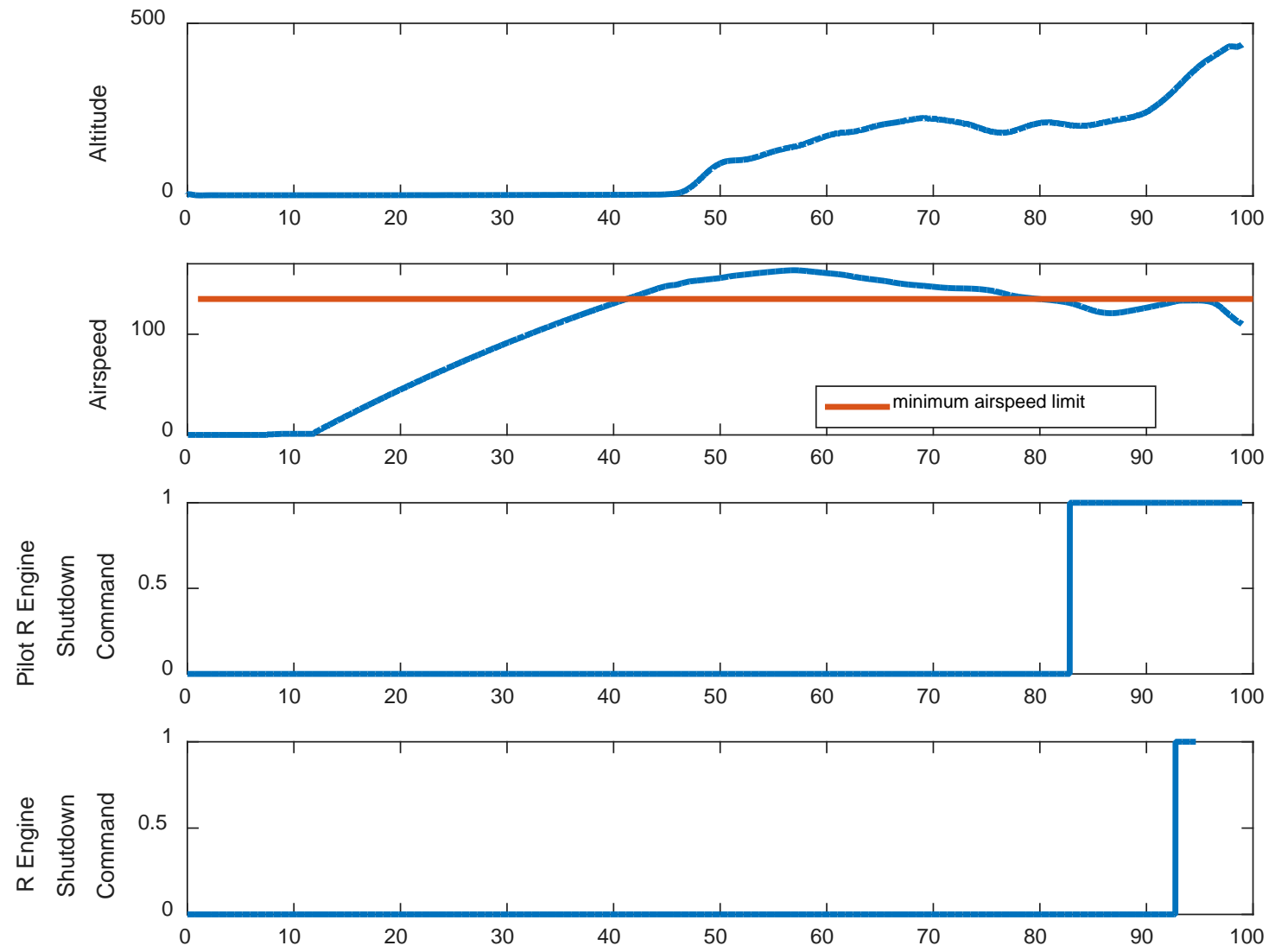

Figure 4.-Example engine shutdown inhibition. 


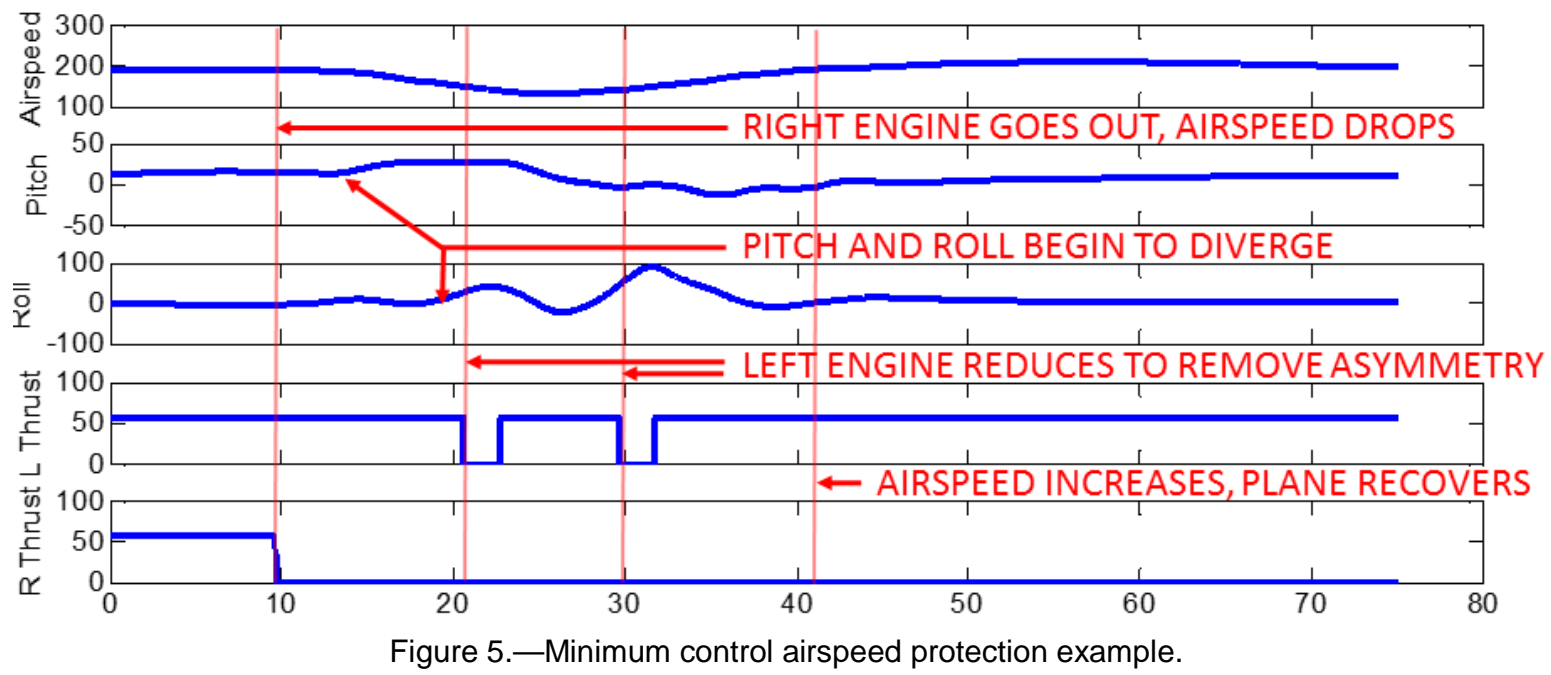

\section{Discussion}

These examples in the previous section build on several technologies. The engine out situation itself is diagnosed without pilot intervention using detection logic related to specific engine variables (note that this algorithm operates independently of the pilot action to shut down the engine). The asymmetric thrust condition, meanwhile, is detected using a thrust estimation scheme. These two diagnoses confirm each other and, taken together, provide knowledge about the engine state, so if a loss-of-control situation becomes imminent, a recovery procedure is initiated.

Previous work has demonstrated that the engine state can be used to determine to what extent engines can augment the flight control to help in recovery of a damaged aircraft (Ref. 33). It has been shown that engines used differentially and together can be effective flight control actuators (Ref. 34). Advanced propulsion control schemes that take advantage of unused safety margins can produce marked improvement in aircraft stability over that provided by traditional propulsion control in these situations. Furthermore, remapping commands from a damaged flight control system to the propulsion system can provide significant handling improvements as compared to manual throttle manipulation (Ref. 28). The intelligent propulsion control architecture has the potential to incorporate such engine capability under the right circumstances.

Pilot checklists are used as the starting point for autonomous operation, although higher level decision-making is often necessary for taking an action. If the situation generally calls for an in-flight engine shutdown, the appropriate checklist would be executed. However, before doing so, there are considerations regarding the aircraft's altitude that must be taken into account, as a pilot would, and the shutdown would probably not be initiated with low airspeed close to the ground as in the example above. Furthermore, for emergency situations, the decisions to initiate these actions could require higher level reasoning capability rather than predefined limits.

Previous research has demonstrated many of the fundamental algorithms required for the architecture to be effective. By populating the architecture with these existing algorithms and integrating them appropriately, several applications of intelligent propulsion control can be readily demonstrated that enable reduced pilot workload, enhanced vehicle performance, and improved engine diagnostic capability. These applications include:

- Minimum control airspeed protection against loss of control for an engine out situation

- Estimation of unmeasured engine variables

- Model-based engine control

- Asymmetric thrust detection and confirmation 
- Detection of a disconnect between the engine power level and throttle position (i.e., stuck throttle)

- Automation of pilot checklist for engine in-flight shutdown

- Inhibition of incorrect engine shutdown

Additionally, previous implementations of integrated flight and propulsion control have demonstrated improved performance, including:

- High crosswind landings

- Augmentation of flight control with propulsion to compensate for stuck, limited, and ineffective flight control surfaces

\section{Lessons Learned}

The architecture is simply a framework. It displays appropriate hierarchy and interaction to offer guidance to the designer, but populating it is still up to the designer. The literature contains many examples of diagnostic and control algorithms that work well individually, so a bottom up approach is logical. However, the details of the integration were not always obvious. Use of multiple diagnostic approaches provided confidence in a conclusion, but much of the higher level functionality was still ad hoc. Pilots and checklists provided direction, but there are many variations on scenarios, and pilot experience is anecdotal, depending significantly on the details of the situation. Furthermore, rare events, or those having no precedent, still require a response that does not make matters worse, which is currently more of a philosophy than a working principle. Thus, the development of this instance of the intelligent propulsion control system relied heavily on combining past work that had been developed in the test bed system, although some higher level responses to situations were developed and refined based on testing (e.g., the low speed OEI example).

It was found that the intelligent propulsion control provides significant advantages during off-nominal situations by improving situational awareness of the pilot and by inhibiting inappropriate crew responses (e.g., reducing the "startle" factor, or helping to assess conflicting information). Conflict resolution logic is important because the sub-elements may generate opposing diagnoses/commands, and an awareness of the flight phase is needed to configure the operation of the sub-elements and to properly set logic priorities.

\section{Conclusions}

An intelligent propulsion control system architecture that enables increased aircraft autonomy has been defined, partially implemented, and demonstrated on some basic scenarios. Some existing algorithms are included, as well as logic to tie the results together and act on them. This structure must still be built up to include higher level functionality that can properly take advantage of the information available. Safety needs to be a major concern in the design of these systems because of its relationship to public confidence. The placeholders in the architecture focus heavily on safety, although it is up to the designer to populate them. With increased integration and information availability, there is also the opportunity to optimize performance. The architecture is designed to accommodate types of algorithms that can coordinate automated, preplanned maneuvers better than a human pilot. As society moves closer to notional acceptance of unpiloted commercial aircraft, primarily as a cost saving measure, the issues addressed by the architecture described herein will become increasingly important. 


\section{References}

1. http://www.boeing.com/resources/boeingdotcom/commercial/services/assets/brochure/pilottechnician outlook.pdf, accessed December 3, 2017.

2. $\quad$ NASA Aeronautics Strategic Implementation Plan, NP-2015-03-1479-HQ.

3. Cummings, M.L., Stimpson, A., and Clamann, M., "Functional Requirements for Onboard Intelligent Automation in Single Pilot Operations,” AIAA 2016-1652, AIAA SciTech Forum, 4-8 January 2016, San Diego, CA.

4. Lowy, J., "Report: Government not ensuring airline pilots' skills are sharp,” Associated Press, Jan 10, 2016, https://www.pbs.org/newshour/politics/report-government-not-ensuring-airline-pilots-skillsare-sharp, accessed November 30, 2017.

5. Boeing Commercial Airplanes, Statistical Summary of Commercial Jet Airplane Accidents Worldwide Operations, 1959-2016, 2017.

6. Cummings, M.L., Gao, F., and Thornburg, K.M., "Boredom in the Workplace: A New Look at an Old Problem,” Human Factors, Vol. 58, No. 2, March 2016, pp. 279-300.

7. National Transportation Safety Board, "Descent Below Visual Glidepath and Impact With Seawall, Asiana Airlines Flight 214, Boeing 777-200ER, HL7742, San Francisco, California, July 6, 2013,” Aircraft Accident Report NTSB/AAR-14/01 PB2014-105984, Notation 8518, Adopted June 24, 2014.

8. National Transportation Safety Board, "Loss of Control on Approach, Colgan Air, Inc., Operating as Continental Connection Flight 3407, Bombardier DHC-8-400, N200WQ, Clarence Center, New York, February 12, 2009,” Aircraft Accident Report NTSB/AAR-10/01, PB2010-910401, Notation 8090A, Adopted February 2, 2010.

9. Fallows, J., "Professional Pilots on the San Francisco Crash: on the "FLCH Trap" and other possibilities,” The Atlantic, July 7, 2013, https://www.theatlantic.com/national/archive/2013/07/ professional-pilots-on-the-san-francisco-crash/277563/, accessed November 1, 2017.

10. National Transportation Safety Board, “Aircraft Accident Report, United Airlines Flight 232, McDonnell Douglas DC-1040, Sioux Gateway Airport, Sioux City, Iowa, July 19, 1989,” PBSO-910406, NTSB/AARSO/06, 1990.

11. Lemaignan, B., "Flying With No Flight Controls: Handling Qualities Analyses of the Baghdad Event,” AIAA-2005-5907, AIAA Atmospheric Flight Mechanics Conference and Exhibit, San Francisco, California, 15-18 August 2005.

12. National Transportation Safety Board, "Loss of Thrust in Both Engines After Encountering a Flock of Birds and Subsequent Ditching on the Hudson River, US Airways Flight 1549, Airbus A320-214, N106US, Weehawken, New Jersey, January 15, 2009,” Aircraft Accident Report Aircraft Accident Report NTSB/AAR-10/03, PB2010-910403, Notation 8082A, Adopted May 4, 2010.

13. Dismukes, R.K. (ed.), Human Error in Aviation, Routledge, New York, 2009, p. xiii.

14. AIA/AECMA: Project Report, "Propulsion System Malfunction Plus Inappropriate Crew Response (PSM + ICR), Volume 1,” 1998.

15. PARC/CAST Flight Deck Automation Working Group, “Operational Use of Flight Path Management Systems,” Federal Aviation Administration, released 11/21/2013.

16. ATA and FAA, “Turbofan Engine Malfunction Recognition and Response Final Report,” 2009.

17. Litt, J.S., Roulette, G., “A Method for Exploiting Redundancy to Accommodate Actuator Limits in Multivariable Systems,” 19th Science Conference sponsored by the U.S. Army, Orlando, Florida, June 20-24, 1994.

18. Litt, J.S., et al., “A Survey of Intelligent Control and Health Management Technologies for Aircraft Propulsion Systems,” AIAA Journal of Aerospace Computing, Information, and Communication 2004, vol.1 no.12 (543-563).

19. National Research Council, “Autonomy Research for Civil Aviation: Toward a New Era of Flight,” 2014.

20. Air Accidents Investigation Branch (AAIB) - United Kingdom, "Report on the Accident to Boeing 737-400 G-OBME Near Kegworth, Leicestershire on 8 January 1989,” AAIB AAR 4/1990. 
21. Aviation Safety Council, Taipei, Taiwan, “Aviation Occurrence Report, 4 February, 2015, TransAsia Airways Flight GE235, ATR72-212A, Loss of Control and Crashed into Keelung River Three Nautical Miles East of Songshan Airport,” ASC-AOR-16-06-001, June 2016.

22. Hueschen, R.M., "Development of the Transport Class Model (TCM) Aircraft Simulation From a Sub-Scale Generic Transport Model (GTM) Simulation,” NASA/TM-2011-217169, August 2011.

23. Csank, J., May, R.D., Litt, J.S., and Guo, T.-H., "Control Design for a Generic Commercial Aircraft Engine,” AIAA-2010-6629, 46th AIAA/ASME/SAE/ASEE Joint Propulsion Conference and Exhibit, Nashville, TN, July 25-28, 2010.

24. May, R.D., Csank, J., Lavelle, T.M., Litt, J.S., and Guo, T.-H., “A High-Fidelity Simulation of a Generic Commercial Aircraft Engine and Controller,” AIAA-2010-6630, 46th

AIAA/ASME/SAE/ASEE Joint Propulsion Conference and Exhibit, Nashville, TN, July 25-28, 2010.

25. Litt, Jonathan S., Sowers, T. Shane, Liu, Yuan, Owen, A. Karl, Guo, Ten-Huei, "Validation of an Integrated Airframe and Turbofan Engine Simulation for Evaluation of Propulsion Control Modes," AIAA-2015-1476, AIAA SciTech 2015, Kissimmee, FL, January 5-9, 2015

26. Chicatelli, A.K., Rinehart, A.W., Sowers, T.S., and Simon, D.L., "Investigation of Asymmetric Thrust Detection With Demonstration in a Real-Time Simulation Testbed,” 51st Joint Propulsion Conference Orlando, FL, July 27-29, 2015.

27. Litt, Jonathan S., Liu, Yuan, Sowers, T. Shane, Owen, A. Karl, Guo, Ten-Huei, "Piloted Simulation Evaluation of a Model-Predictive Automatic Recovery System to Prevent Vehicle Loss of Control on Approach,” AIAA-2014-0036, AIAA Atmospheric Flight Mechanics Conference, National Harbor, MD, January 13-17, 2014.

28. Litt, Jonathan S., Guo, Ten-Huei, Sowers, T. Shane, Chicatelli, Amy K., Fulton, Christopher E., May, Ryan D., and Owen, A. Karl, "Pilot-in-the-Loop Evaluation of a Yaw Rate to Throttle Feedback Control with Enhanced Engine Response,” AIAA-2012-5027, AIAA Guidance, Navigation, and Control Conference, Minneapolis, MN, Aug. 13-16, 2012.

29. Csank, J.T. and Connolly, J.W., "Model-Based Engine Control Architecture With an Extended Kalman Filter,” AIAA-2016-1623, Scitech 2016, San Diego, California, January 4-8, 2016.

30. May, R.D. and Garg, S., "Reducing Conservatism in Aircraft Engine Response Using Conditionally Active Min-Max Limit Regulators,” GT2012-70017, ASME Turbo Expo 2012, Copenhagen, Denmark, June 11-15, 2012.

31. Armstrong, J.B., and Simon, D.L., "Constructing an Efficient Self-Tuning Aircraft Engine Model for Control and Health Management Applications,” 2012 Annual Conference of the Prognostics and Health Management Society Minneapolis, Minnesota, September 23-27, 2012.

32. Simon, D.L., Garg, S., "Optimal Tuner Selection for Kalman Filter-Based Aircraft Engine Performance Estimation,”GT2009-59684, Turbo Expo 2009, Orlando, FL, June 8-12, 2009.

33. Liu, Y., Litt, J.S., Sowers, T.S., Owen, A.K., Guo, T-H., “Application and Evaluation of Control Modes for Risk-Based Engine Performance Enhancements,” AIAA-2014-3637, 50th AIAA/ASME/SAE/ASEE Joint Propulsion Conference, Cleveland, OH, July 28-30, 2014.

34. Tucker, T., "Touchdown: The Development of Propulsion Controlled Aircraft at NASA Dryden," Monographs in Aerospace History \#16, NASA History Office, 1999. 

